\title{
Investigation of Symptom Status, Body Perception Levels and Symptoms of Anxiety and Depression in Breast Cancer Patients Receiving Paclitaxel: A Prospective Longitudinal Study
}

GAMZE GÖKÇE CEYLAN ( $\sim$ gmzgkc@gmail.com )

Ankara Şehir Hastanesi: Ankara Sehir Hastanesi https://orcid.org/0000-0001-8731-7657

Zehra GÖK METiN

Hacettepe University: Hacettepe Universitesi

Research Article

Keywords: anxiety, body perception, breast cancer, depression, nursing, paclitaxel

Posted Date: June 1st, 2021

DOl: https://doi.org/10.21203/rs.3.rs-491095/v1

License: (c) (i) This work is licensed under a Creative Commons Attribution 4.0 International License. Read Full License 


\section{Abstract}

Purpose: This study aimed to investigate symptom status, body perception level changes and the symptoms of anxiety and depression in breast cancer patients receiving Paclitaxel.

Methods: This descriptive, and prospective study was conducted with 84 breast cancer patients receiving paclitaxel regimen. "Chemotherapy Symptom Assessment Scale (C-SAS)", "Body Perception Scale (BPS)" and "Hospital Anxiety and Depression Scale (HADS)" were applied at five time points $(T \otimes, T \otimes, T \otimes, T \otimes, T \bigotimes)$. Data was analyzed using descriptive statistics, Wilcoxon, Friedman, Cochrane Q and Spearman's correlation tests.

Results: The frequency of needling and numbness in hands and feet, pain, and skin or nail changes significantly increased in the subsequent assessment points $(T \otimes, T \otimes, T \otimes$, and $T \nabla)$ compared to the initial assessment $(T \otimes)(p<0.05)$. The mean scores of BPS significantly decreased at $T \otimes, T Q$, and $T \otimes(p<0.01)$. The mean scores of the anxiety subscale of the HADS scale decreased at the T2, T3, and T4 ( $<<0.01)$, and the mean scores of the depression subscale significantly increased at the T3, T4, and T5 ( $<<0.01)$.

Conclusions: The findings underscore the need for oncology nurses to provide comprehensive training sessions on effective symptom management, changes in body perception levels, and alleviation of the symptoms of anxiety and depression in breast cancer patients receiving paclitaxel. In this way, the physiological symptom burden that occurs in patients may be alleviated, and negative changes in body perception, anxiety and depression symptoms may be decreased.

\section{Introduction}

Breast cancer (BC) is the most common type of cancer among women worldwide, causing significant rates of mortality and morbidity [1, 2]. In recent years, adjuvant and neoadjuvant systemic therapies have started to take an important place in BC treatment to reduce the associated mortality rate, in addition to the classical treatment methods such as surgery, chemotherapy, and radiotherapy [3].

Paclitaxel is frequently preferred during adjuvant and neoadjuvant therapies [4]. Paclitaxel is a taxane group drug and can be administered weekly (12 weeks) or every 21 days (four cycles) after four cycles of adriamycin-cyclophosphamide (AC) treatment in patients with earlystage $B C$ [5-7]. With the increasing clinical use of paclitaxel in BC, it is reported that therapeutic response, survival, and disease-free survival rates have increased [6].

Paclitaxel often causes significant symptoms such as neutropenia, nausea, vomiting, diarrhea, oral mucositis, amenorrhea, alopecia, arthralgia, myalgia, peripheral neuropathy, skin and nail changes, liver and renal toxicity, and hypersensitivity reactions in BC patients depending on the number of cycles and the dose administered [5,6]. Based on literature, nail changes [8], arthralgia and myalgia [9] and neurotoxicity [10] are frequently seen in patients with BC. In particular, during the weekly administered paclitaxel regimen, patients are found feeling uncomfortable due to arthralgia and myalgia, taste changes, peripheral neuropathy, fatigue, cognitive problems, and insomnia [11]. In addition, neurotoxicity is reported to be associated with the increasing cumulative dose of the paclitaxel [10]. Patients with BC receiving paclitaxel also experience anxiety, depression and decrease in body perception due to physiological effects of paclitaxel including alopecia, changes in sexual life, menstrual disorders, weight changes and changes in nails/skin [12-14].

Parallel to the increasing symptom status during the $\mathrm{BC}$ treatment, patients find it increasingly difficult to adapt to the treatment. Changes in physical, cognitive, and emotional statuses may also cause a decline in the body perception. [15]. Body perception in BC patients is negatively affected during the paclitaxel regimen as a result of edema, weight changes, alopecia, differentiation in skin color and nails, oral mucositis, menstrual cycle disorders and sexual life problems [16, 17]. At the same time, as in many cultures, imputed meanings related to aesthetic appearance, femininity, attractiveness, sexuality, and motherhood in Turkish culture makes the treatment process even more difficult for patients with BC $[18,19]$. Several studies have also highlighted that chemotherapy and mastectomy, which have an important place in the BC treatment, negatively affect the body perception in BC patients $[12,13,20]$.

Another clinical situation that needs to be considered is that emotional changes, including distress, anxiety, and depression in BC patients. During BC treatment, experienced symptoms, decrease in the body perception and increase in anxiety, patients have more difficulty coping with the treatment process, and they constitute a risky group for depression [16]. Previous studies conducted with BC patients reported that alopecia, weight changes, fatigue, and difficulties in sexual life are directly related to higher anxiety and depression levels in those undergoing surgery and chemotherapy $[14,21,22]$. Besides, numerous studies have emphasized that the anxiety levels are higher in the first year after a BC diagnosis [23], which gradually decrease during the treatment [24].

In the literature, no studies have been found that investigated changes in symptom status, body perception, and the symptoms of anxiety and depression prospectively in patients with BC scheduled to receive paclitaxel regimen. Therefore, this study aimed to determine the symptom

Page 2/15 
status, body perception changes, and the symptoms of anxiety and depression in patients with BC for a total of 12 weeks. It is assumed that determining the time intervals in which the risk of anxiety and depression become evident during the treatment may provide to plan comprehensive training programs and counseling sessions for $\mathrm{BC}$ patients and may reduce the symptom burden as well as the deterioration in body perception.

\section{Research Questions}

- How do the symptom status change in $\mathrm{BC}$ patients during the paclitaxel regimen?

- How do body perception levels change in $\mathrm{BC}$ patients during the paclitaxel regimen?

- How do the symptoms of anxiety and depression change in BC patients during the paclitaxel regimen?

\section{Methods}

\section{Study design and setting}

This descriptive and prospective study was conducted between July 29, 2019 and June 15, 2020 at three centers located in XXX, Turkey. Participants were recruited from the outpatient clinics of the Departments of Clinical Oncology of the three local public hospitals. All patients selected for this study received a total of 12 paclitaxel infusions in the oncology outpatient clinic once a week, for a total of 12 weeks.

\section{Participants}

The universe of the study consisted of patients with $\mathrm{BC}$ who received the first cure of the paclitaxel regimen in the daytime treatment units. The patients who met the inclusion criteria were included in the study without using any sampling method. Considering the correlation coefficient as 0.30 between the BPS and the HADS total scores, the sample size was calculated at least 84 patients with a power of $80 \%$ through the G Power 3.1.10 program. Patients aged between 18 and 65 years, who were diagnosed of BC and had completed four cycles of $\mathrm{AC}$ regimen prior to the paclitaxel regimen and all the 12 cycles of the paclitaxel were included in the study. Those who had communication problems, had a psychiatric diagnosis (major depression, etc.), had a different cancer diagnosis, were receiving radiotherapy, using relaxation techniques or antidepressants during the study, could not complete 12 cycles of the paclitaxel regimen, and were not willing to participate were excluded from the study. In this context, a total of 88 patients were assessed, four patients were excluded due to following reasons: did not want to continue the study $(n=2)$, could not be reached after the fourth cycle $(n=1)$ and did not want to receive her treatment due to fear of coronavirus-19 disease (COVID-19) $(n=1)$. Finally, this study was completed with 84 patients.

\section{Data Collection Tools}

\section{Demographic and clinical information form}

This form developed based on the literature [4, 5, 6, 25], and consisted of age, height, weight, body mass index, educational level, marital status, income level, employment status, whether having children or not, accompanying comorbidities, duration of BC diagnosis, BC stage, previous treatments, mastectomy status, people living together with, and residency in XXX.

\section{Chemotherapy Symptom Assessment Scale (C-SAS)}

This scale was developed to determine the symptom status of cancer patients receiving chemotherapy treatment [19]. The Turkish version of the C-SAS was studied by Aslan et al. (2006) [18]. It includes 24 different symptoms that may occur during chemotherapy. Patients are asked to identify the status of experiencing each symptom as "yes"/"no". Since each symptom is evaluated separately, the arithmetic mean values are not used in evaluating the scale scores. In the Turkish validity and reliability study of the scale, the Cronbach alpha coefficient was found as $0.82[18,19]$. In this study, Cronbach's alpha coefficient was calculated as 0.62 .

\section{Body Perception Scale (BPS)}

This scale was developed by Secord and Jourard (1953) [26]. It contains 40 five-point likert-type questions about body region or function. These 40 items include five assessment criteria related to each organ or body function (starting from 1 = "I do not like" to 5 = "I like very much"). Total score that can be obtained from the scale varies between 40 and 200. An increase in the total score indicates that a person's satisfaction with the part or functionality that makes up his/her body increases. The Turkish validity and reliability study of the scale was conducted by Hovardaoğlu (1993) and the Cronbach alpha coefficient was found as 0.91 [27]. In this study, the Cronbach's alpha coeffıcient value was calculated to be 0.84 .

\section{Hospital Anxiety and Depression Scale (HADS)}

Page 3/15 
HADS was developed by Zigmond and Snaith (1983) [28] to determine the risk status for anxiety and depression in patients with physical disorders, and its Turkish version was studied by Aydemir et al. (1997) [29]. It includes 14 questions and two sub-dimensions as anxiety and depression. Seven questions (odd numbered) measure anxiety (HAD-A) while the other seven questions (even numbered) measure depression (HAD-D). In the scale, questions are scored on a four-point Likert scale, each ranging from 0 to 3 . The lowest score that a patient can get from each sub-dimension is 0 , and the highest score is 21 . As the total scores increase, patients are considered at risk for anxiety and depression. In the Turkish validity and reliability study of the scale, the Cronbach alpha coefficient was found as 0.85 and 0.77 for the anxiety and depression sub-dimensions, respectively [29]. In this study, the Cronbach's alpha coefficient values were calculated as 0.86 and 0.79 for the anxiety and depression sub-dimensions in this study, respectively.

\section{Data collection procedure}

Baseline data $\left(T_{1}\right)$ were collected on the day of the first paclitaxel infusion, before the first infusion was given, using the demographic and clinical information form, C-SAS, BPS, and HADS from the patients who met the inclusion criteria. The patients were prospectively followed by the principal investigator (PI) during the paclitaxel regimen for a total of 12 weeks. The C-SAS, BPS, and the HADS were reapplied to the patients by the PI at the end of the first cycle (first week - $\mathrm{T}_{2}$ ), fourth cycle (fourth week - $\mathrm{T}_{3}$ ), eighth cycle (eighth week - $\mathrm{T}_{4}$ ), and twelfth cycle (twelfth week $-T_{5}$ ) during the paclitaxel regimen (Fig. 1).

\section{Statistical analysis}

Data analysis was performed using "IBM Statistics 23.0" statistical package program. Descriptive statistics (mean, median, standard deviation, minimum, maximum, percentage, and frequency) were used in the evaluation of the socio-demographic data. Data were analyzed for normality using Shapiro Wilk Test. The Cochran's Q test was used to determine the changes in the frequency of symptoms. Since the BPS and HADS data were not normally distributed, Pearson's correlation test was used to determine the relationship between the two scales. The Friedman Test and the Wilcoxon test were used to examine the changes in BPS and HADS scores as per the paclitaxel cycles. When a statistically significant difference was found, the advanced post-hoc test (Bonferroni test) was utilized to determine the assessment point ( $T 区$, $T \bigotimes, T \bigotimes, T \bigotimes$, or $T \bigotimes$ ) that caused the difference. The statistical significance value was set at $p<0.05$ in the study.

\section{Ethical considerations}

Ethical approval was obtained from XXX University Non-Interventional Clinical Research Ethics Committee, and institutional permissions were obtained from hospital administrations. All information was collected in accordance with the Declaration of Helsinki. Informed consent forms were obtained from all the patients included in the study. The PI gave information to the patients about the importance, purpose, and contributions of the study in the first interview received the contact numbers of the patients and applied the data collection tools using a faceto-face interview technique.

\section{Results}

The descriptive characteristics of the patients are given in Table 1 . The majority of the sample had completed primary school (60.7\%) and did not work (73.8\%); however, half of the patients reported having a mid-level income. The great majority of participants were married (85.7\%) and had children (89.3\%). $47.6 \%$ of the patients had stage-2 BC, $77.4 \%$ had undergone breast surgery and chemotherapy treatments before, and $26.2 \%$ had come from other cities to receive their scheduled treatment. The big majority of patients (94\%) lived with their family, and nearly half (45.2\%) of those had at least one additional chronic disease. The mean age of patients was $49.57 \pm 8.14$ years. The mean value of the body mass index was $29.49 \pm 5.50$, and the average number of children was $2.14 \pm 1.04$. The mean time of diagnosis was $5.51 \pm 1.66$ months; the time since diagnosis was $3-6$ months in $81 \%$ of the patients.

Changes in symptom frequency among the patients were prospectively evaluated at five different time points ( $T \bigotimes, T \otimes, T \bigotimes, T \bigotimes$, and $T \otimes)$ during the 12-week paclitaxel regimen (Table 2). When the symptoms of nausea and vomiting (after treatment), constipation, weight loss or weight gain, changes in appetite, problems with the eyes, feelings of extraordinary fatigue, headaches, anxiety or distress, pessimism and sadness, changes in sexual life, and changes in the menstrual cycle were compared with symptom statuses of the baseline assessment (TQ), a significant decrease was observed in the aforementioned symptoms in all the subsequent measurements $(T \otimes, T \bigotimes, T \bigotimes$ and $T \otimes)(p<0.05)$. Besides, the frequency of feeling needling, numbness, and pain in the hands and feet increased in the subsequent assessments $(T Q, T Q, T Q$ and $T Q$ ) compared to the baseline assessment $(T Q)(p<0.05)$. In addition, according to the baseline assessment $\left(T_{1}\right)$ and the assessment at the end of the first cycle $\left(T_{2}\right)$, the increase in the frequency of sleep disturbances in the fifth assessment $\left(T_{5}\right)$ cycle remained statistically significant $(p<0.05)$. Finally, the frequency of skin and nail changes gradually increased from T2 to T5 $(p<0.05)$. However, the differences between the measurements $\left(T_{1}, T \bigotimes, T \bigotimes, T \bigotimes, T \bigotimes\right)$ were not statistically significant in terms of nausea and vomiting (before treatment), diarrhea, dyspnea, signs of infection, bleeding or bruising, hair loss, weakness, and problems with the mouth and throat $(p>0.05)$. 
Regarding the changes in the mean BPS scores of the patients during the paclitaxel regimen, the corresponding scores were $137.75 \pm 13.72$ at $\mathrm{T} \otimes, 130.53 \pm 14.62$ at $\mathrm{T} \otimes, 132.33 \pm 12.01$ at $\mathrm{T}_{3}, 129.59 \pm 12.62$ at $\mathrm{T}_{4}$, and $124.07 \pm 10.43$ at $\mathrm{T} \otimes(\mathrm{Table} 3$ ). When comparing the changes in the mean

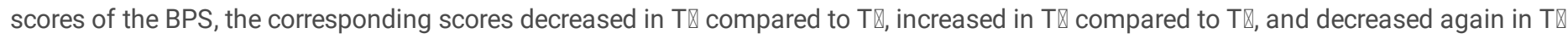

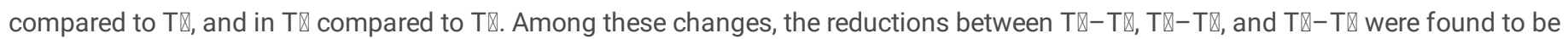
statistically significant $(\mathrm{p}<0.05)$. In addition, in paired comparisons, the reductions between $T \nabla-T \nabla, T \nabla-T \nabla, T \nabla-T \nabla$, and $T \nabla-T \nabla$ measurements were statistically significant $(p<0.05)$.

During the paclitaxel regimen in this study, the mean scores of the HAD-A sub-dimension were $6.60 \pm 4.74$ at $T \nabla, 5.63 \pm 3.86$ at $T \otimes, 4.47 \pm 3.33$ at $T_{3}, 4.17 \pm 3.01$ at $T \nabla$, and $4.29 \pm 3.15$ at $T \nabla$. When Table 4 is examined, it can be seen that the mean scores of the HAD-A decreased in $T \nabla$ compared to $T \nabla$ and $T \otimes$ and in $T \otimes$ and $T \nabla$ compared to $T \otimes$; the mean scores increased in $T \nabla$ compared to $T_{4}$. $T$ he reductions between $T \nabla-T \nabla$ and $T \nabla-T \nabla$ assessments were statistically significant $(p<0.05)$. Also, the reductions between the $T \nabla-T \nabla, T \nabla-T \otimes, T \nabla-T \nabla, a n d T \nabla-T \nabla$ measurements were statistically significant based on the paired comparison tests $(p<0.05)$.

The changes in the mean scores of the HAD-D sub-dimension based on the paclitaxel cures are presented in Table 4. Accordingly, it was found to be $6.00 \pm 4.16$ at $\mathrm{T} \otimes, 5.64 \pm 3.37$ at $\mathrm{T}_{2}, 6.13 \pm 3.65$ at $\mathrm{T} \nabla, 6.90 \pm 3.23$ at $\mathrm{T} \otimes$, and $7.44 \pm 2.85$ at $\mathrm{T} \nabla$. When Table 4 is examined, it can be seen that the mean depression scores decreased in $T \otimes$ compared to $T \otimes$, increased in $T \otimes$ compared to $T \nabla$ and $T \nabla$, and increased again in $T_{3}$ and $T_{5}$

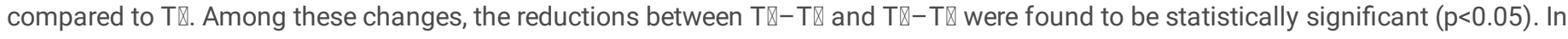
addition, the differences between the $T \nabla-T \nabla, T \nabla-T \nabla, T \nabla-T \nabla$, and $T \nabla-T \nabla$ measurements were statistically significant based on paired comparisons $(p<0.05)$.

\section{Discussion}

In this prospective study, we investigated the symptom status, body perception level changes and the symptoms of anxiety and depression in $\mathrm{BC}$ patients receiving Paclitaxel treatment using 5 different measurement points. While frequency of symptoms nausea-vomiting, fatigue, headaches, anxiety-distress decreased, needling, numbness, pain in the hands and feet, sleep disturbances, and skin-nail changes increased during the paclitaxel regimen. Similar to our findings, neuropathy, skin and nail toxicities, and arthralgia and myalgia were frequently reported in patients receiving paclitaxel regimen $[8,30,31,32]$. A study evaluating the symptom status before and after the treatment in $B C$ patients also reported that anxiety decreased, and pain increased [33]. Bao et al. (2016) [34] confirmed that 58.4\% of the BC patients receiving taxane chemotherapy had numbness in their hands and feet. In contrast to the present study, Azim et al. (2011) showed that women receiving adjuvant therapy had more serious sexual problems compared to those receiving other treatments [35]. In the current study, BC patients receiving paclitaxel regimen after four cycles of $A C$ chemotherapy were followed within the scope of the standard paclitaxel regimen used only in the treatment of early-stage BC. Due to the high side effect profile of the AC cycle, many symptoms were found to be quite high at the beginning of the cycle and relatively lower at the end of the first cycle. The researchers assumed that the gradual decrease in the symptom frequency perceived by the $\mathrm{BC}$ patients in the later stages of adjuvant paclitaxel courses in the study sample could be due to easier tolerance for the paclitaxel therapy as against for the systematic and aggressive chemotherapy protocol, including the AC treatment.

This study also evaluated the changes in body perception levels during the paclitaxel regimen. Based on the findings, the body perception scores of the patients were found to be highest at $T \otimes$, and lowest at $T_{5}$. Similarly, Villar et al. (2017) found that the body perception levels of the breast cancer patients receiving chemotherapy decreased in the last evaluation compared to the first evaluation [33]. Two studies carried out in Brazil and Israel reported that the body perception levels of breast cancer patients receiving chemotherapy decreased by $74.8 \%$ and $80.9 \%$, respectively [36, 37]. In a systematic review conducted by Paterson et al. (2016), the body perception of breast cancer patients was negatively affected in 35 out of the 36 studies [14]. It is presumed that the changes in symptom status such as alopecia, skin and nail changes, and neuropathic pain in breast cancer patients during the paclitaxel regimen might be influential on the perceived negative changes in body perception. These conditions may lead to a significant decrease in the body perception levels over time.

Another important finding of this study was that the mean scores of the HAD-A subscale decreased in the first four measurements ( $T_{1}, T_{2}$, $T_{3}$, and $\mathrm{T}_{4}$ ) and relatively increased in the last measurement $\left(\mathrm{T}_{5}\right)$. Similarly, Villar et al. (2017) reported that the anxiety levels decreased significantly following the chemotherapy and radiotherapy treatments in breast cancer patients [33]. Moreira \& Canavarro (2010) also concluded that the anxiety levels of breast cancer patients decreased during the period following surgery and chemotherapy [22]. Bergerot et al. (2017) stated that the anxiety levels of the cancer patients were highest on the first day and lowest on the last day of chemotherapy [38]. Considering all the findings of the studies, higher anxiety levels in the patients before the paclitaxel regimen may be related to the initiation of a new chemotherapy regimen and the uncertainties that may be experienced during the process. The decrease in the anxiety levels of the $\mathrm{BC}$ patients over time may be due to the relatively lower and moderate symptom severity during the paclitaxel regimen, and the improvement of physiological and psychological, individual coping strategies along with the increase in knowledge of and experience related to $\mathrm{BC}$ and its treatment. 
We have also examined the changes in depression scores. Accordingly, the depression scores decreased at the end of $T_{2}$ compared to $T_{1}$ and gradually increased at $T_{3}, T_{4}$, and $T_{5}$. Confirming the findings of this study, Byar et al. (2006) had earlier reported that depression levels were low at the beginning and increased as the treatment progressed in BC patients receiving adjuvant chemotherapy [39]. Oh \& Cho (2020) also stated that while the depression rate was $4 \%$ in South Korean BC patients before the chemotherapy started, it reached $30 \%$ after the chemotherapy [40]. Considering all the results, the lower levels of of depression at the end of the first cycle and the higher levels as the course progressed may be related to the symptoms, the lack of comprehensive management of these symptoms, and the changes in body perception and anxiety levels following 12 weeks of paclitaxel regimen. The increase in the symptoms of depression at the end of the treatment may be attributed to the uncertainties in the prognose and the treatment options to be continued.

\section{Limitations}

Since the treatment hours were at the same time in all the three study centers, some patients were missed and could never include in the study. Another limitation is that the first, fourth, eighth, and the twelfth (end of cure) assessments of 36 patients were compulsorily completed via phone interviews due to the announcement of the COVID-19 pandemic and the suspension of research in hospitals in Turkey as March 2020 .

\section{Conclusions}

To the best of our knowledge, this is the first study evaluating BC patients receiving paclitaxel in terms of symptom statutes, body perception levels, and anxiety and depression symptoms at five different time points during the paclitaxel protocol. This study showed that a comprehensive follow-up of BC patients by oncology nurses becomes important to alleviate the symptoms, improve body perception and decrease the anxiety and depression. In this context, the nurses should simultaneously evaluate the changes in the symptom status, body perception levels, and the anxiety-depression symptoms during the paclitaxel regimen, and should take precautions early enough, and thus make important contributions to the patients.

\section{Declarations}

\section{Funding}

This research did not receive any specific grant from funding agencies in the public, commercial, or not-for-profit sectors.

Authors' contributions: Gamze Gökçe Ceylan is the first author of this study. She has responsibility in conceptualization, data curation, formal analysis, investigation, methodology, resources, visualization, writing. Zehra Gök Metin is the co-author of the study. She has responsibility in data curation, methodology, project administration, supervision, validation, writing-review \& editing. Final version of this manuscript is approved by all of the authors.

Acknowledgements: The authors would like to thank all the participants, the nurses and administrative staff working in Hacettepe University Oncology Hospital, Dr. A.Y. Ankara Oncology Hospital and Ankara City Hospital. Without the participants' voluntary participation, and support of the nurses and administrative staff, this study would not have been possible. The authors also express their thank to head of medical oncology unit Prof. Dr. Ömür Berna Çakmak Öksüzoğlu, and nurse Zeynep Sipahi Karslı for their collaboration and great support.

Availability of data and material: The datasets generated during and/or analysed during the current study are available from the corresponding author on reasonable request.

Code availability: Not applicable

Ethics approval: Ethical approval was obtained from Hacettepe University Non-Interventional Clinical Research Ethics Committee (2019/0610), and institutional permissions were obtained from hospital administrations to start the study. All information was collected in accordance with the Declaration of Helsinki.

Consent to participate: Informed consent was obtained from all individual participants included in the study.

Consent for publication: Informed consent was obtained from all individual participants included in the study.

Conflicts of interest: The authors declare they have no conflict of interest.

\section{Author information}


Affiliations

Ankara City Hospital, Ankara, Turkey; Bilkent Street No:1 Çankaya/ANKARA.

Gamze GOKCE CEYLAN

Hacettepe University Faculty of Nursing, Internal Medicine Nursing Department, Turkey Nursing Department, Ankara, Turkey.

Zehra GOK METIN

Corresponding author

Correspondence to Gamze GÖKÇE CEYLAN.

\section{References}

1. Mungan, I., Doğru, O., Aygen, E. \& Dağlı, A. F. 2019. The relations of vascular endothelial growth factor-C and lymph node metastasis in breast cancer patients. Journal of Surgery and Medicine, 3, 124-127.

2. WHO. 2018 [Erişim Tarihi: 05.12.2018]. International Agency for Research on Cancer [Internet]. [Online]. Available: https://gco.iarc.fr/today/data/factsheets/cancers/20-Breast-fact-sheet.pdf. [Accessed].

3. Desantis, C. E., Ma, J., Goding Sauer, A., Newman, L. A. \& Jemal, A. 2017. Breast cancer statistics, 2017, racial disparity in mortality by state. CA: a cancer journal for clinicians, 67, 439-448.

4. Rowinsky, E. K. \& Donehower, R. C. 1995. Paclitaxel (taxol). N Engl J Med, 332, 1004-1014.

5. Shapiro, C. L. \& Recht, A. 2001. Side effects of adjuvant treatment of breast cancer. New England Journal of Medicine, 344, $1997-2008$.

6. Erdemoğlu, N. \& Şener, B. 2000. The antitumor effects of the taxane class compounds. Ankara Ecz Fak Derg, $29,77-90$.

7. BC Cancer Kemoterapi Protokolleri. (2019,1 July). [Internet]. https://www.kanser.org/saglik/.

8. Sibaud, V., Lebœuf, N. R., Roche, H., Belum, V. R., Gladieff, L., Deslandres, M., Montastruc, M., Eche, A., Vigarios, E. \& Dalenc, F. 2016. Dermatological adverse events with taxane chemotherapy. Eur J Dermato, 26, 427-443

9. Reeves, B. N., Dakhil, S. R., Sloan, J. A., Wolf, S. L., Burger, K. N., Kamal, A., Le-Lindqwister, N. A., Soori, G. S., Jaslowski, A. J. \& Kelaghan, J. 2012. Further data supporting that paclitaxel-associated acute pain syndrome is associated with development of peripheral neuropathy: North Central Cancer Treatment Group trial N08C1. Cancer, 118, 5171-5178.

10. Pace, A., Nisticò, C., Cuppone, F., Bria, E., Galiè, E., Graziano, G., Natoli, G., Sperduti, I., Jandolo, B. \& Calabretta, F. 2007. Peripheral neurotoxicity of weekly paclitaxel chemotherapy: a schedule or a dose issue? Clinical breast cancer, 7, $550-554$.

11. Boehmke, M.M. \& Dickerson, S.S. 2005. Symptom, symptom experiences, and symptom distress encountered by women with breast cancer undergoing current treatment modalities. Cancer nursing, 28, 382-389.

12. Begovic-Juhant, A., Chmielewski, A., Iwuagwu, S. \& Chapman, L. A. 2012. Impact of body image on depression and quality of life among women with breast cancer. J Psychosoc Oncol, 30, 446-460.

13. Choi, E. K., Kim, I. R., Chang, O., Kang, D., Nam, S. J., Lee, J. E., Lee, S. K., Im, Y. H., Park, Y. H. \& Yang, J. H. 2014. Impact of chemotherapyinduced alopecia distress on body image, psychosocial well-being, and depression in breast cancer patients. Psycho-Oncology, 23, 11031110.

14. Paterson, C., Lengacher, C. A., Donovan, K. A., Kip, K. E. \& Tofthagen, C. S. 2016. Body image in younger breast cancer survivors: a systematic review. Cancer nurs, 39, E39-E58.

15. Tazegül, Ü. 2018. Sporcularin kişilik özellikleri ile bedenlerini beğenmeleri arasindaki ilişkinin belirlenmesi. Elektronik Sosyal Bilimler Dergisi, 17, 1518-1526.

16. Cordero, M. J. A., Villar, N. M., Sánchez, M. N., Pimentel-Ramírez, M. L., García-Rillo, A. \& Valverde, E. G. 2015. Breast cancer and body image as a prognostic factor of depression: a case study in México City. Nutr hosp, 31, 371-379.

17. Prates, A. C. L., Freitas-Junior, R., Prates, M. F. O., Veloso, M. D. F. \& Barros, N. D. M. 2017. Influence of body image in women undergoing treatment for breast cancer. Rev Bras Ginecol Obstet, 39, 175-183.

18. Aslan, Ö., Vural, H., Kömürcü, Ş. \& Özet, A. 2006. Kemoterapi Alan Kanser Hastalarina Verilen Eğitimin Kemoterapi Semptomlarina Etkisi. CÜ Hemsirelik Yüksekokulu Dergisi, 10, 15-28.

19. Brown, V., Sitzia, J., Richardson, A., Hughes, J., Hannon, H. \& Oakley, C. 2001. The development of the Chemotherapy Symptom Assessment Scale (C-SAS): a scale for the routine clinical assessment of the symptom experiences of patients receiving cytotoxic chemotherapy. International journal of nursing studies, 38, 497-510.

Page $7 / 15$ 
20. Grogan, S. \& Mechan, J. 2017. Body image after mastectomy: A thematic analysis of younger women's written accounts. J Health Psychol, 22, 1480-1490.

21. Cairo Notari, S., Notari, L., Favez, N., Delaloye, J. F. \& Ghisletta, P. 2017. The protective effect of a satisfying romantic relationship on women's body image after breast cancer: a longitudinal study. Psycho-oncology, 26, 836-842.

22. Moreira, H. \& Canavarro, M. C. 2010. A longitudinal study about the body image and psychosocial adjustment of breast cancer patients during the course of the disease. Euro j oncol nurs, 14, 263-270.

23. Burgess, C., Cornelius, V., Love, S., Graham, J., Richards, M. \& Ramirez, A. 2005. Depression and anxiety in women with early breast cancer: five year observational cohort study. Bmj, 330, 702.

24. İzci, F., Özdem, G., İlgün, A. S., Ağaçayak, F., Duymaz, T., Erdoğan, Z., Alço, G., Elbüken, F., Öztürk, A. \& Ordu, Ç. 2020. Pre-Treatment and Post-Treatment Anxiety, Depression, Sleep and Sexual Function Levels in Patients with Breast Cancer. Euro J Breast Health, 16, 219.

25. Sevinç, A. I. 2015. Erken evre meme kanserinde tedavi seçenekleri. In: IN: AYDıN S, A. T., EDITORS. (ed.) Tüm Yönleriyle Meme Kanseri. Adana: Nobel Kitabevi.

26. Secord, P. F. \& Jourard, S. M. 1953. The appraisal of body-cathexis: body-cathexis and the self. J Consult Psychol, $17,343-7$.

27. Hovardaoğlu, S. 1993. Vücut algısı ölçeği. Psikiyatri, Psikoloji, Psikofarmakoloji (3P) Dergisi, 1, 26-7.

28. Zigmond, A. S. \& Snaith, R. P. 1983. The hospital anxiety and depression scale. Acta psychiatrica scandinavica, 67, $361-370$.

29. Aydemir, O. 1997. Hastane anksiyete ve depresyon olcegi Turkce formunun gecerlilik ve guvenilirligi. Turk Psikiyatri Derg., 8, $187-280$.

30. Abudayyak, M., Yalçin, C. Ö. \& Korkut, E. 2018. Kemoterapi İle İndüklenmiş Periferal Nöropatinin Tedavisi ve Önlenmesine Yönelik Farmakolojik Yaklaşımlar. FABAD Journal of Pharmaceutical Sciences, 43, 113-127.

31. Marupudi, N. I., Han, J. E., Li, K. W., Renard, V. M., Tyler, B. M. \& Brem, H. 2007. Paclitaxel: a review of adverse toxicities and novel delivery strategies. Expert opinion on drug safety, 6, 609-621

32. Marks, D. H., Qureshi, A. \& Friedman, A. 2018. Evaluation of prevention interventions for taxane-induced dermatologic adverse events: a systematic review. Jama Dermatology, 154, 1465-1472.

33. Villar, R. R., Fernández, S. P., Garea, C. C., Pillado, M., Barreiro, V. B. \& Martín, C. G. 2017. Quality of life and anxiety in women with breast cancer before and after treatment. Revista Latino-Americana de Enfermagem, 25.

34. Bao, T., Basal, C., Seluzicki, C., Li, S. Q., Seidman, A. D. \& Mao, J. J. 2016. Long-term chemotherapy-induced peripheral neuropathy among breast cancer survivors: prevalence, risk factors, and fall risk. Breast cancer research and treatment, 159, $327-333$.

35. Azim Jr, H., De Azambuja, E., Colozza, M., Bines, J. \& Piccart, M. 2011. Long-term toxic effects of adjuvant chemotherapy in breast cancer. Annals of oncology, 22, 1939-1947.

36. Pud, D. 2015. The psychometric properties of the Hebrew version of the Memorial Symptom Assessment Scale (MSAS-Heb) in patients with breast cancer. Journal of Pain and Symptom Management, 49, 790-795.

37. Guedes, T. S. R., De Oliveira, N. P. D., Holanda, A. M., Reis, M. A., Da Silva, C. P., E Silva, B. L. R., De Camargo Cancela, M. \& De Souza, D. L. B. 2018. Body image of women submitted to breast cancer treatment. Asian Pacific journal of cancer prevention: APJCP,19, 1487.

38. Bergerot, C. D., Mitchell, H.-R., Ashing, K. T. \& Kim, Y. 2017. A prospective study of changes in anxiety, depression, and problems in living during chemotherapy treatments: effects of age and gender. Supportive Care in Cancer, 25, 1897-1904.

39. Byar, K. L., Berger, A. M., Bakken, S. L. \& Cetak, M. A. Impact of adjuvant breast cancer chemotherapy on fatigue, other symptoms, and quality of life. Oncology nursing forum, 2006. Oncology Nursing Society, E18.

40. Oh, P.-J. \& Cho, J.-R. 2020. Changes in fatigue, psychological distress, and quality of life after chemotherapy in women with breast cancer: a prospective study. Cancer nursing, 43, E54-E60.

\section{Tables}

Table 1. Participants' characteristics $(n=84)$ 


\begin{tabular}{|c|c|c|c|}
\hline Variable & Category & Number (n) & Percent (\%) \\
\hline \multirow[t]{4}{*}{ Educational Level } & Primary school & 51 & 60.7 \\
\hline & Middle School & 10 & 11.9 \\
\hline & High school & 19 & 22.6 \\
\hline & Associate / License & 4 & 4.8 \\
\hline \multirow[t]{2}{*}{ Marital Status } & Single & 12 & 14.3 \\
\hline & Married & 72 & 85.7 \\
\hline \multirow[t]{3}{*}{ Income Level } & Low & 40 & 47.6 \\
\hline & Middle & 42 & 50.0 \\
\hline & High & 2 & 2.4 \\
\hline \multirow[t]{2}{*}{ Employment } & Not working & 62 & 73.8 \\
\hline & Working & 22 & 26.2 \\
\hline \multirow[t]{2}{*}{ Having a Child } & Absent & 9 & 10.7 \\
\hline & Present & 75 & 89.3 \\
\hline \multirow[t]{2}{*}{ People that Living Together } & Alone & 5 & 6.0 \\
\hline & With family & 79 & 94.0 \\
\hline \multirow[t]{2}{*}{ Residency in XXX } & Yes & 62 & 73.8 \\
\hline & No & 22 & 26.2 \\
\hline \multirow[t]{2}{*}{ Comorbidities } & Present & 38 & 45.2 \\
\hline & Absent & 46 & 54.8 \\
\hline \multirow[t]{3}{*}{ Breast Cancer Stage } & Stage 1 & 10 & 11.9 \\
\hline & Stage 2 & 40 & 47.6 \\
\hline & Stage 3 & 34 & 40.5 \\
\hline \multirow[t]{2}{*}{ Previous Treatments } & Chemotherapy & 19 & 22.6 \\
\hline & Surgery and Chemotherapy & 65 & 77.4 \\
\hline \multirow[t]{2}{*}{ Mastectomy Status } & No & 21 & 25.0 \\
\hline & Yes & 63 & 75.0 \\
\hline Variable & Min & Max & $X \pm S D^{*}$ \\
\hline Age & 29 & 64 & $49.57 \pm 8.14$ \\
\hline BMI & 17.92 & 46.48 & $29.49 \pm 5.50$ \\
\hline Duration of Breast Cancer Diagnosis (months) & 3 & 12 & $5.51 \pm 1.66$ \\
\hline Number of children & 0 & 4 & $2.14 \pm 1.04$ \\
\hline
\end{tabular}

* $\mathrm{X} \pm \mathrm{SD}=$ Mean, Standard Deviation, BMI: Body Mass Index

Table 2. The Changes in Chemotherapy Symptom Assessment according to paclitaxel cycles $(n=84)$ 


\begin{tabular}{|c|c|c|c|c|c|c|c|c|c|c|c|c|c|c|}
\hline \multirow[t]{2}{*}{ Variable } & \multirow[t]{2}{*}{ Status } & \multicolumn{2}{|l|}{$\mathrm{TQ}$} & \multicolumn{2}{|l|}{$\mathrm{TQ}$} & \multicolumn{2}{|l|}{$\mathrm{TQ}$} & \multicolumn{2}{|l|}{$\mathrm{TQ}$} & \multicolumn{2}{|l|}{$\mathrm{TQ}$} & \multirow[t]{2}{*}{$P$ value } & \multirow[t]{2}{*}{ Q } & \multirow{2}{*}{$\begin{array}{l}\text { Difference } \\
\text { Between } \\
\text { End of Cure } \\
\text { Measurements }\end{array}$} \\
\hline & & (n) & (\%) & (n) & $(\%)$ & (n) & $(\%)$ & (n) & (\%) & (n) & $(\%)$ & & & \\
\hline \multirow{2}{*}{$\begin{array}{l}\text { Nausea- } \\
\text { vomiting } \\
\text { before } \\
\text { treatment }\end{array}$} & Present & 2 & 2.4 & 2 & 2.4 & 2 & 2.4 & 1 & 1.2 & $0^{*}$ & 0 & \multirow[t]{2}{*}{$p=0.934$} & \multirow[t]{2}{*}{0.429} & \multirow[t]{2}{*}{-} \\
\hline & Absent & 82 & 97.6 & 82 & 97.6 & 82 & 97.6 & 83 & 98.8 & 84 & 100 & & & \\
\hline \multirow[t]{4}{*}{$\begin{array}{l}\text { Nausea after } \\
\text { treatment }\end{array}$} & Present & 75 & 89.3 & 19 & 22.6 & 10 & 11.9 & 7 & 8.3 & 10 & 11.9 & \multirow[t]{4}{*}{$p<0.001$} & \multirow[t]{4}{*}{188.960} & $\begin{array}{l}\mathrm{T} 1-\mathrm{T} 2 \\
(\mathrm{p}<0.001 \\
\mathrm{Q}=0.667)\end{array}$ \\
\hline & & & & & & & & & & & & & & $\begin{array}{l}\text { T1-T3 } \\
(p<0.001 \\
Q=0.774)\end{array}$ \\
\hline & Absent & 9 & 10.7 & 65 & 77.4 & 74 & 88.1 & 77 & 91.7 & 74 & 88.1 & & & $\begin{array}{l}\text { T1-T4 } \\
(p<0.001 \\
Q=0.774)\end{array}$ \\
\hline & & & & & & & & & & & & & & $\begin{array}{l}\text { T1-T5 } \\
(\mathrm{p}<0.001 \\
\mathrm{Q}=0.810)\end{array}$ \\
\hline \multirow[t]{2}{*}{$\begin{array}{l}\text { Vomiting } \\
\text { after } \\
\text { treatment }\end{array}$} & Present & 19 & 22.6 & 3 & 3.6 & 1 & 1.2 & $0 *$ & 0 & $0 *$ & 0 & \multirow[t]{2}{*}{$p<0.001$} & \multirow[t]{2}{*}{29.200} & $\begin{array}{l}\text { T1-T2 } \\
(\mathrm{p}<0.001 \\
0=-0.190)\end{array}$ \\
\hline & Absent & 65 & 77.4 & 81 & 96.4 & 83 & 98.8 & 84 & 100 & 84 & 100 & & & $\begin{array}{l}\text { T1-T3 } \\
(p<0.001 \\
Q=-0.214)\end{array}$ \\
\hline \multirow[t]{6}{*}{ Constipation } & Present & 44 & 52.4 & 31 & 36.9 & 21 & 25.0 & 15 & 17.9 & 15 & 17.9 & \multirow[t]{6}{*}{$p<0.001$} & \multirow[t]{6}{*}{43.461} & $\begin{array}{l}\text { T1-T3 } \\
(\mathrm{p}<0.001 \\
\mathrm{Q}=0.274)\end{array}$ \\
\hline & & & & & & & & & & & & & & $\begin{array}{l}\text { T1-T4 } \\
(\mathrm{p}<0.001 \\
\mathrm{Q}=0.345)\end{array}$ \\
\hline & & & & & & & & & & & & & & T1-T5 \\
\hline & Absent & 40 & 40.7 & 53 & 63.1 & 63 & 75.0 & 69 & 82.1 & 69 & 82.1 & & & $\mathrm{Q}=0.345)$ \\
\hline & & & & & & & & & & & & & & $\begin{array}{l}\text { T2-T4 } \\
(\mathrm{p}<0.001 \\
\mathrm{Q}=0.190)\end{array}$ \\
\hline & & & & & & & & & & & & & & $\begin{array}{l}\text { T2-T5 } \\
(\mathrm{p}=0.026 \\
\mathrm{Q}=0.190)\end{array}$ \\
\hline \multirow[t]{2}{*}{ Diarrhea } & Present & 15 & 17.9 & 3 & 3.6 & 10 & 11.9 & 10 & 11.9 & 10 & 11.9 & \multirow[t]{2}{*}{0.052} & \multirow[t]{2}{*}{9.385} & \multirow[t]{2}{*}{-} \\
\hline & Absent & 69 & 82.1 & 81 & 96.4 & 74 & 88.1 & 74 & 88.1 & 74 & 88.1 & & & \\
\hline \multirow[t]{4}{*}{ Pain } & Present & 35 & 41.7 & 59 & 70.2 & 54 & 64.3 & 58 & 69.0 & 64 & 76.2 & \multirow[t]{4}{*}{$p<0.001$} & 33.026 & $\begin{array}{l}\mathrm{T} 1-\mathrm{T} 2 \\
(\mathrm{p}<0.001 \\
\mathrm{Q}=0.286)\end{array}$ \\
\hline & & & & & & & & & & & & & & $\begin{array}{l}\text { T1-T3 } \\
(p=0.006 \\
Q=0.226)\end{array}$ \\
\hline & Absent & 49 & 58.3 & 25 & 29.8 & 30 & 35.7 & 26 & 31.0 & 20 & 23.8 & & & $\begin{array}{l}\mathrm{T} 1-\mathrm{T} 4 \\
(\mathrm{p}<0.001 \\
\mathrm{Q}=0.274)\end{array}$ \\
\hline & & & & & & & & & & & & & & $\begin{array}{l}\text { T1-T5 } \\
(\mathrm{p}<0.001 \\
\mathrm{Q}=0.345)\end{array}$ \\
\hline Dyspnea & Present & 5 & 6.0 & 6 & 7.1 & 6 & 7.1 & 6 & 7.1 & 6 & 7.1 & 0.997 & 0.154 & - \\
\hline & Absent & 79 & 94.0 & 78 & 92.9 & 78 & 92.9 & 78 & 92.9 & 78 & 92.9 & & & \\
\hline Signs of & Present & 2 & 2.4 & 3 & 3.6 & 3 & 3.6 & 3 & 3.6 & 3 & 3.6 & 0.991 & 0.286 & - \\
\hline
\end{tabular}




\begin{tabular}{|c|c|c|c|c|c|c|c|c|c|c|c|c|c|c|}
\hline & Absent & 82 & 97.6 & 81 & 96.4 & 81 & 96.4 & 81 & 96.4 & 81 & 96.4 & & & \\
\hline \multirow{2}{*}{$\begin{array}{l}\text { Bleeding or } \\
\text { bruising }\end{array}$} & Present & 1 & 1.2 & $0 *$ & 0 & 2 & 2.4 & $0 *$ & 0 & 1 & 1.2 & \multirow[t]{2}{*}{0.717} & \multirow[t]{2}{*}{0.667} & \multirow[t]{2}{*}{-} \\
\hline & Absent & 83 & 98.8 & 84 & 100 & 82 & 97.6 & 84 & 100 & 83 & 98.8 & & & \\
\hline \multirow[t]{8}{*}{$\begin{array}{l}\text { Pins and } \\
\text { needles in } \\
\text { hands, feet }\end{array}$} & Present & 24 & 28.6 & 20 & 23.8 & 38 & 45.2 & 57 & 67.9 & 74 & 88.1 & \multirow[t]{8}{*}{$p<0.001$} & \multirow[t]{8}{*}{111.957} & $\begin{array}{l}\text { T1-T4 } \\
(p<0.001, Q= \\
0.393)\end{array}$ \\
\hline & & & & & & & & & & & & & & $\begin{array}{l}\text { T1-T5 } \\
(\mathrm{p}<0.001, \mathrm{Q}= \\
0.595)\end{array}$ \\
\hline & & & & & & & & & & & & & & $\begin{array}{l}\text { T2-T3 } \\
(p=0.003, Q= \\
0.214)\end{array}$ \\
\hline & & & & & & & & & & & & & & $\begin{array}{l}\text { T2-T4 } \\
(p<0.001, Q= \\
0.440)\end{array}$ \\
\hline & Absent & 60 & 71.4 & 64 & 76.2 & 46 & 54.8 & 27 & 32.1 & 10 & 11.9 & & & $\begin{array}{l}\text { T2-T5 } \\
(p<0.001, Q= \\
0.643)\end{array}$ \\
\hline & & & & & & & & & & & & & & $\begin{array}{l}\text { T3-T4 } \\
(p=0.018, Q= \\
0.226)\end{array}$ \\
\hline & & & & & & & & & & & & & & $\begin{array}{l}\text { T3-T5 } \\
(p<0.001, Q= \\
0.429)\end{array}$ \\
\hline & & & & & & & & & & & & & & $\begin{array}{l}\text { T4-T5 } \\
(\mathrm{p}<0.005, \mathrm{Q}= \\
0.202)\end{array}$ \\
\hline \multirow[t]{4}{*}{$\begin{array}{l}\text { Problems } \\
\text { with the skin } \\
\text { or nails }\end{array}$} & Present & 68 & 81.0 & 55 & 65.5 & 63 & 75.0 & 72 & 85.7 & 79 & 94.0 & \multirow[t]{4}{*}{$p<0.001$} & \multirow[t]{4}{*}{30.481} & $\begin{array}{l}\text { T2-T4 } \\
(p=0.003, Q= \\
0.202)\end{array}$ \\
\hline & & & & & & & & & & & & & & T2-T5 \\
\hline & Absent & 16 & 19.0 & 29 & 34.5 & 21 & 25.0 & 12 & 14.3 & 5 & 6.0 & & & $0.286)$ \\
\hline & & & & & & & & & & & & & & $\begin{array}{l}\text { T3-T5 } \\
(p=0.006, Q= \\
0.190)\end{array}$ \\
\hline \multirow[t]{2}{*}{ Hair loss } & Present & $84^{*}$ & 100 & 0 * & 0 & 3 & 3.6 & 2 & 2.4 & 7 & 8.3 & \multirow[t]{2}{*}{$p=0.148$} & \multirow[t]{2}{*}{3.818} & \multirow[t]{2}{*}{-} \\
\hline & Absent & 0 & 0 & 84 & 100 & 81 & 96.4 & 82 & 97.6 & 77 & 91.7 & & & \\
\hline \multirow{2}{*}{$\begin{array}{l}\text { Problems } \\
\text { with the } \\
\text { mouth and } \\
\text { throat }\end{array}$} & Present & 65 & 77.4 & 52 & 61.9 & 54 & 64.3 & 57 & 67.9 & 59 & 70.2 & \multirow[t]{2}{*}{$p=0.058$} & \multirow[t]{2}{*}{9.117} & \multirow[t]{2}{*}{ - } \\
\hline & Absent & 19 & 22.6 & 32 & 38.1 & 30 & 35.7 & 27 & 32.1 & 25 & 29.8 & & & \\
\hline \multirow[t]{4}{*}{$\begin{array}{l}\text { Change in } \\
\text { appetite }\end{array}$} & Present & 72 & 85.7 & 41 & 48.8 & 54 & 64.3 & 44 & 52.4 & 43 & 51.2 & \multirow[t]{4}{*}{$p<0.001$} & \multirow[t]{4}{*}{33.990} & $\begin{array}{l}\mathrm{T} 1-\mathrm{T} 2 \\
(\mathrm{p}<0.001, \mathrm{Q}= \\
0.369)\end{array}$ \\
\hline & & & & & & & & & & & & & & $\begin{array}{l}\text { T1-T3 } \\
(p=0.039, Q= \\
0.214)\end{array}$ \\
\hline & Absent & 12 & 14.3 & 43 & 51.2 & 30 & 35.7 & 40 & 47.6 & 41 & 48.8 & & & $\begin{array}{l}\mathrm{T} 1-\mathrm{T} 4 \\
(\mathrm{p}<0.001, \mathrm{Q}= \\
0.333)\end{array}$ \\
\hline & & & & & & & & & & & & & & $\begin{array}{l}\text { T1-T5 } \\
(\mathrm{p}<0.001, \mathrm{Q}= \\
0.345)\end{array}$ \\
\hline \multirow{2}{*}{$\begin{array}{l}\text { Losing or } \\
\text { gaining } \\
\text { weight }\end{array}$} & Present & 50 & 59.5 & 12 & 14.3 & 34 & 40.5 & 32 & 38.1 & 37 & 44.0 & \multirow[t]{2}{*}{$p<0.001$} & \multirow[t]{2}{*}{33.368} & \multirow{2}{*}{$\begin{array}{l}\text { T1-T2 } \\
(p<0.001, Q= \\
0.452)\end{array}$} \\
\hline & Absent & 34 & 40.5 & 72 & 85.7 & 50 & 59.5 & 52 & 61.9 & 47 & 56.0 & & & \\
\hline
\end{tabular}


T1-T4

$(\mathrm{p}<0.005, \mathrm{Q}=$

0.214)

T2-T3

$(\mathrm{p}=0.004, \mathrm{Q}=$

-0.262 )

T2-T4

$(\mathrm{p}=0.012, \mathrm{Q}=$

-0.238 )

T2-T5

$(\mathrm{p}=0.001, \mathrm{Q}=$

$-0.298)$

$\begin{array}{lllllllllllllll}\text { Problems } & \text { Present } & 51 & 60.7 & 7 & 8.3 & 15 & 17.9 & 16 & 19.0 & 29 & 34.5 & \mathbf{p}<0.001 & 75.139 & \text { T1-T2 }\end{array}$

with the eyes

$\begin{array}{llllllllllll} & & & \end{array}$

$(\mathrm{p}<0.001$

$0.524)$

T1-T3

$(\mathrm{p}<0.001, \mathrm{Q}=$

$0.429)$

T1-T4

$(\mathrm{p}<0.001, \mathrm{Q}=$

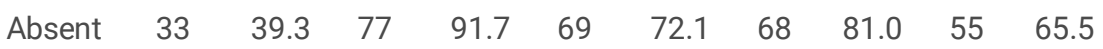

0.417)

T1-T5

$(\mathrm{p}=0.001, \mathrm{Q}=$

0.262 )

T2-T5

$(p=0.001, Q=$

-0.262 )

\begin{tabular}{|c|c|c|c|c|c|c|c|c|c|c|c|c|c|}
\hline \multirow[t]{2}{*}{ Fatigue } & Present & $84^{*}$ & 100 & 68 & 81.0 & 73 & 86.9 & 74 & 88.1 & 75 & 89.3 & \multirow[t]{2}{*}{$p=0.332$} & \multirow[t]{2}{*}{3.412} \\
\hline & Absent & 0 & 0 & 16 & 19.0 & 11 & 13.1 & 10 & 11.9 & 9 & 10.7 & & \\
\hline Feeling & Present & 66 & 78.6 & 10 & 11.9 & 20 & 23.8 & 10 & 11.9 & 20 & 23.8 & $p<0.001$ & 123.529 \\
\hline
\end{tabular}

exceptionally

tired

$\begin{array}{lllllllllll}\text { Absent } & 18 & 21.4 & 74 & 88.1 & 64 & 76.2 & 74 & 88.1 & 64 & 76.2\end{array}$

$(\mathrm{p}<0.001, \mathrm{Q}=$

-0.536 )

$\begin{array}{lllllllllll}\text { Absent } & 18 & 21.4 & 74 & 88.1 & 64 & 76.2 & 74 & 88.1 & 64 & 76.2\end{array}$

T1-T4

$(\mathrm{p}<0.001, \mathrm{Q}=$

$-0.655)$

T1-T5

$(\mathrm{p}<0.001, \mathrm{Q}=$

$-0.536)$

$\begin{array}{lllllllllllllll}\begin{array}{l}\text { Difficulty } \\ \text { sleping }\end{array} & \text { Present } & 35 & 41.7 & 35 & 41.7 & 41 & 48.8 & 42 & 50.0 & 51 & 60.7 & \mathbf{p}=0.016 & 12.169 & \begin{array}{l}\text { T1-T5 } \\ (\mathrm{p}=0.027\end{array}\end{array}$

sleeping

$(\mathrm{p}=0.027, \mathrm{Q}=$

$0.190)$

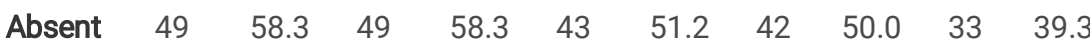

T2-T5

$(\mathrm{p}=0.027, \mathrm{Q}=$

$0.190)$

$\begin{array}{lllllllllllllll}\text { Headaches } & \text { Present } & 48 & 57.1 & 26 & 31.0 & 40 & 47.6 & 30 & 35.7 & 32 & 38.1 & \mathrm{p}=0.001 & 18.491 & \mathrm{~T} 1-\mathrm{T} 2\end{array}$

$(\mathrm{p}=0.001, \mathrm{Q}=$

$0.262)$

$\begin{array}{llllllllllll}\text { Absent } & 36 & 42.9 & 58 & 69.0 & 44 & 52.4 & 54 & 64.3 & 52 & 61.9 & \text { T1-T4 }\end{array}$

$(\mathrm{p}=0.018, \mathrm{Q}=$

0.214)

$\begin{array}{lllllllllllllll}\begin{array}{l}\text { Feeling } \\ \text { anxious or }\end{array} & \text { Present } & 61 & 72.6 & 47 & 56.0 & 44 & 52.4 & 48 & 57.1 & 43 & 51.2 & \mathrm{p}=0.008 & 13.673 & \begin{array}{l}\mathrm{T} 1-\mathrm{T} 3 \\ (\mathrm{p}=0.021\end{array}\end{array}$

anxious or

$-0.202)$

$\begin{array}{lllllllllll}\text { Absent } & 23 & 27.4 & 37 & 44.0 & 40 & 47.6 & 36 & 42.9 & 41 & 48.8\end{array}$

T1-T5

$(\mathrm{p}=0.011, \mathrm{Q}=$

$-0.214)$

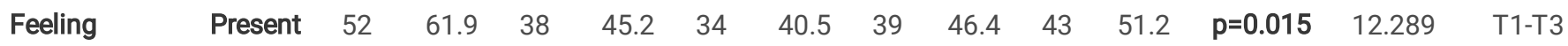

Page 12/15 


\begin{tabular}{|c|c|c|c|c|c|c|c|c|c|c|c|c|c|c|}
\hline $\begin{array}{l}\text { pessimistic, } \\
\text { upset }\end{array}$ & Absent & 32 & 38.1 & 46 & 54.8 & 50 & 59.5 & 45 & 53.6 & 41 & 48.8 & & & $\begin{array}{l}(p=0.011, Q= \\
-0.214)\end{array}$ \\
\hline \multirow[t]{4}{*}{$\begin{array}{l}\text { Change in } \\
\text { sexual life }\end{array}$} & Present & 54 & 64.3 & $0 *$ & 0 & 5 & 6.0 & 5 & 6.0 & 1 & 1.2 & \multirow[t]{4}{*}{$p<0.001$} & \multirow[t]{4}{*}{129.542} & $\begin{array}{l}\text { T1-T3 } \\
(\mathrm{p}<0.001, \mathrm{Q}= \\
0.543)\end{array}$ \\
\hline & & & & & & & & & & & & & & $\begin{array}{l}\text { T1-T4 } \\
(p<0.001, Q=\end{array}$ \\
\hline & Absent & 30 & 35.7 & 84 & 100 & 79 & 94.0 & 79 & 94.0 & 83 & 98.8 & & & $0.583)$ \\
\hline & & & & & & & & & & & & & & $\begin{array}{l}\text { T1-T5 } \\
(\mathrm{p}<0.001, \mathrm{Q}= \\
0.631)\end{array}$ \\
\hline \multirow{4}{*}{$\begin{array}{l}\text { Change in } \\
\text { the } \\
\text { menstrual } \\
\text { cycle }\end{array}$} & Present & 46 & 54.8 & 1 & 1.2 & 2 & 2.4 & 1 & 1.2 & 1 & 1.2 & \multirow[t]{4}{*}{$p<0.001$} & \multirow[t]{4}{*}{160.280} & $\begin{array}{l}\text { T1-T2 } \\
(p<0.001, Q= \\
-0.536)\end{array}$ \\
\hline & & & & & & & & & & & & & & $\begin{array}{l}\text { T1-T3 } \\
(p<0.001, Q= \\
-0.524)\end{array}$ \\
\hline & Absent & 38 & 45.2 & 83 & 98.8 & 82 & 97.6 & 83 & 98.8 & 83 & 98.8 & & & $\begin{array}{l}\text { T1-T4 } \\
(p<0.001, Q= \\
-0.536)\end{array}$ \\
\hline & & & & & & & & & & & & & & $\begin{array}{l}\text { T1-T5 } \\
(\mathrm{p}<0.001, \mathrm{Q}= \\
-0.536)\end{array}$ \\
\hline
\end{tabular}

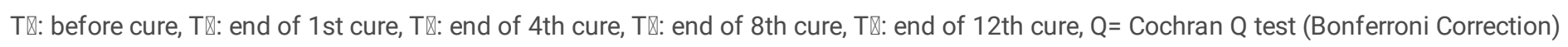

* Since the value on the boxes are "0", it could not be included in the statistical analysis.

Table 3. The mean scores of Body Perception Scale according to paclitaxel cycles $(n=84)$

\begin{tabular}{|c|c|c|c|c|c|}
\hline Measurement & Min & Max & $\mathrm{X} \pm \mathrm{SD}$ & Test Statistics & Difference \\
\hline$T \otimes$ & 92 & 185 & $137.75 \pm 13.72$ & \multirow{7}{*}{$p<0.001 *$} & $T \otimes-T \otimes\left(p<0.001^{\star \star}, Z=-5.164\right)$ \\
\hline \multirow[t]{2}{*}{$\mathrm{T} \otimes$} & \multirow{2}{*}{95} & \multirow{2}{*}{180} & \multirow{2}{*}{$130.53 \pm 14.62$} & & 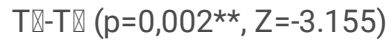 \\
\hline & & & & & $T \otimes-T Q\left(p<0.001^{\star *}, Z=-6.009\right)$ \\
\hline$T \otimes$ & 104 & 163 & $132.33 \pm 12.01$ & & 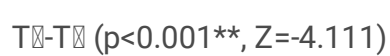 \\
\hline \multirow[t]{2}{*}{$\mathrm{TQ}$} & \multirow[t]{2}{*}{104} & \multirow[t]{2}{*}{185} & \multirow[t]{2}{*}{$129.59 \pm 12.62$} & & $T \bigotimes-T \rrbracket\left(p=0.008^{* *}, Z=-2.671\right)$ \\
\hline & & & & & $T \mathbb{T Q} \otimes\left(p<0.001^{\star *}, Z=-5.679\right)$ \\
\hline$T \nabla$ & 102 & 159 & $124.07 \pm 10.43$ & & $T \rrbracket-T \rrbracket\left(p<0.001^{* *}, Z=-4.691\right)$ \\
\hline
\end{tabular}

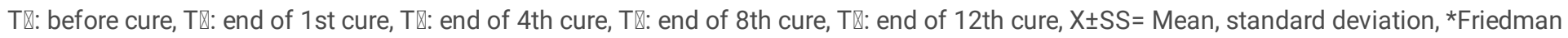
Test, **Wilcoxon Test

Table 4. The mean scores of anxiety and depression sub-dimension of HADS according to paclitaxel cycles $(n=84)$ 


\begin{tabular}{|c|c|c|c|c|c|c|}
\hline & Measurement & Min & Max & $X \pm S D$ & Test Statistics & Difference \\
\hline \multirow{7}{*}{ Anxiety } & $\mathrm{T} \otimes$ & 0 & 20 & $6.60 \pm 4.74$ & \multirow{7}{*}{$p<0.001 *$} & $T \rrbracket-T \rrbracket(p=0.038 * *, Z=-2.072)$ \\
\hline & TX & 0 & 17 & $563+386$ & & $T \otimes-T \otimes\left(p<0.001^{\star \star}, Z=-4.012\right)$ \\
\hline & & & & & & $T \otimes-T \otimes\left(p<0.001^{\star *}, Z=-4.616\right)$ \\
\hline & $\mathrm{T} \otimes$ & 0 & 14 & $4.47 \pm 3.33$ & & $T \otimes-T \otimes\left(p<0.001^{* *}, Z=-3.988\right)$ \\
\hline & $\mathrm{TQ}$ & 0 & 12 & $4.17 \pm 3.01$ & & $T \nabla-T \otimes\left(p=0.003^{\star *}, Z=-2.939\right)$ \\
\hline & & & & & & $T \otimes-T \otimes\left(p=0.003^{\star *}, Z=-2.981\right)$ \\
\hline & $\mathrm{TQ}$ & 0 & 17 & $4.29 \pm 3.15$ & & $T \otimes-T \otimes(p=0.001 * *, Z=-3.213)$ \\
\hline \multirow{6}{*}{ Depression } & T1 & 0 & 18 & $6.00 \pm 4.16$ & \multirow{6}{*}{$p<0.001 *$} & $T \otimes-T \otimes\left(p=0.027^{\star \star}, Z=-2.215\right)$ \\
\hline & $\mathrm{T} 2$ & 0 & 18 & $5.64 \pm 3.37$ & & $T \rrbracket-T \rrbracket\left(p=0.002^{\star *}, Z=-3.162\right)$ \\
\hline & T3 & 0 & 14 & $6.13 \pm 3.65$ & & $T \otimes-T \otimes(p=0.001 * \star, Z=-3.476)$ \\
\hline & & & & & & $T \otimes-T \otimes\left(p<0.001^{* *}, Z=-4.355\right)$ \\
\hline & T4 & 1 & 16 & $6.90 \pm 3.23$ & & $T \otimes-T \otimes\left(p=0.002^{\star *}, Z=-3.029\right)$ \\
\hline & T5 & 0 & 15 & $7.44 \pm 2.85$ & & $T \otimes-T \otimes\left(p=0.018^{* *}, Z=-2.368\right)$ \\
\hline
\end{tabular}

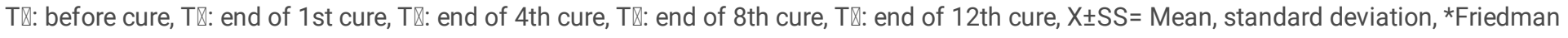
Test, **Wilcoxon Test

\section{Figures}


Patients come to the day treatment unit at 08.00

Providing a laboratory sample and waiting for the results (approximately 1 hour) to determine whether they can receive chemotherapy

* In Hacettepe University and Ankara City Hospital, this procedure is done one day before.

Physician's evaluation of laboratory results for compliance

* In Hacettepe University and Ankara City Hospital, this procedure is done one day before.

If the doctor approves the patient's laboratory results, the chemotherapy protocol is sent to the pharmacy and the patients' medication is prepared.

* In Hacettepe University and Ankara City Hospital, this procedure is done one day before.

Vital signs of the patients are measured and recorded, premedication drugs are prepared, chemotherapy infusion path (port needle or vascular) is prepared, premedication drugs are administered.

Paclitaxel agent is prepared in the pharmacy as specified in the protocol and delivered to the day therapy unit.

Nurses start the chemotherapy infusion by checking identity, and follow the patient for sensitivity reactions until the end of the infusion (approximately 1 hour).

Figure 1

Steps to apply the paclitaxel regimen 